\title{
Isolation of Methyl Troposulfenin from Phaeobacter inhibens
}

Phippen, Christopher B. W.; Jørgensen, Cecilie M.; Bentzon-Tilia, Mikkel; Gotfredsen, Charlotte Held; Larsen, Thomas O.; Gram, Lone; Sonnenschein, Eva C.

Published in:

Journal of Natural Products

Link to article, DOI:

10.1021/acs.jnatprod.8b01097

Publication date:

2019

Document Version

Peer reviewed version

Link back to DTU Orbit

Citation (APA):

Phippen, C. B. W., Jørgensen, C. M., Bentzon-Tilia, M., Gotfredsen, C. H., Larsen, T. O., Gram, L., \& Sonnenschein, E. C. (2019). Isolation of Methyl Troposulfenin from Phaeobacter inhibens. Journal of Natural Products, 82(5), 1387-1390. https://doi.org/10.1021/acs.jnatprod.8b01097

\section{General rights}

Copyright and moral rights for the publications made accessible in the public portal are retained by the authors and/or other copyright owners and it is a condition of accessing publications that users recognise and abide by the legal requirements associated with these rights.

- Users may download and print one copy of any publication from the public portal for the purpose of private study or research.

- You may not further distribute the material or use it for any profit-making activity or commercial gain

- You may freely distribute the URL identifying the publication in the public portal 


\section{Isolation of Methyl Troposulfenin from Phaeobacter}

\section{inhibens}

Christopher B. W. Phippen, ${ }^{\dagger}$ Cecilie M. Jørgensen, ${ }^{\dagger}{ }^{\S}$ Mikkel Bentzon-Tilia, ${ }^{\dagger}$ Charlotte Held Gotfredsen, ${ }^{\ddagger}$ Thomas O. Larsen,$^{\dagger}$ Lone Gram, ${ }^{\dagger}$ Eva C. Sonnenschein ${ }^{\dagger} *$

${ }^{\dagger}$ Department of Biotechnology and Biomedicine, Technical University of Denmark, Søltofts Plads 221, Kongens Lyngby, 2800, Denmark

Department of Chemistry, Technical University of Denmark, Kemitorvet 207, Kongens Lyngby, 2800, Denmark

$\S$ Current address: Novo Nordisk A/S, Novo Nordisk Park, 2760 Måløv, Denmark

* Corresponding author: Eva C. Sonnenschein, phone: +45 45252518, e-mail: evaso@bio.dtu.dk 
ABSTRACT: An S-methylated analogue of tropodithietic acid (TDA, 1), methyl troposulfenin (2), was isolated from the marine alphaproteobacterium Phaeobacter inhibens. The structure was elucidated by NMR and HRMS. Its inhibitory effect against the fish pathogen Vibrio anguillarum was 4-fold to 100-fold lower than the one of the known antibacterial compound, TDA. Methyl troposulfenin lacks the acidic protons of TDA, indicating that the methylation turns the potent antibacterial TDA into an inactive compound and thereby, this analysis supports the proposed mode of action of TDA. 
Although land-based agriculture has a history of thousands of years, large-scale aquaculture is a comparatively recent phenomenon. Aquaculture is becoming a very important source of food for human consumption, with the total mass of farmed fish surpassing that of wild catches in $2014 .^{1}$ In order for the growing population to maintain a healthy diet, an increase in industrial fish farming is necessary not to risk further depletion of wild fish stocks. Intensive fish farming has the downside of high mortality rates due to pathogenic microorganisms. ${ }^{2}$ Whilst grown fish often can be vaccinated, juvenile fish and larvae, which have a less developed immune system, require other disease control measures. The alphaproteobacterium Phaeobacter inhibens is a wellestablished fish probiotic that decreases mortality of pathogen-infected cod larvae. ${ }^{3-6}$ This antibacterial effect is hypothesized to be largely due to tropodithietic acid, TDA (1) (Figure 1). ${ }^{4,5}$ TDA is particular interesting for application because resistance of pathogenic bacteria towards the molecule has not been detected. ${ }^{7,8}$ TDA is a disulfide containing tropone derivative ${ }^{9}$ and no natural analogues have been described to date. It was originally isolated as its tautomer thiotropocin ${ }^{10}$ but computational chemistry has shown that $\mathbf{1}$ and thiotropocin exist as a pair of interconverting tautomers. ${ }^{11}$ Few natural products are known from $P$. inhibens, with those known including the algicidal roseobacticides and roseochelins. ${ }^{12-14}$ Roseobacticides A - K share chemical features with $\mathbf{1}$ and thiotropocin, such as a core tropone ring and sulfur substitution. The biosynthesis of the roseobacticides is proposed to be interlinked with that of $1 .{ }^{14,15} \mathrm{In}$ contrast, the recently reported roseochelins are a hybrid enzymatic and non-enzymatic natural product which is composed of a bi-aryl 2-naphthoic acid/dimethoxy-phenol system. ${ }^{13}$ Here, we describe the isolation and structure elucidation of methyl troposulfenin (2), a new analog of TDA (1), from P. inhibens DSM 17395 that demonstrated a loss of antibacterial activity against the 
fish pathogenic bacterium Vibrio anguillarum in comparison to $\mathbf{1}$ and together with structural comparison of $\mathbf{1}$ and $\mathbf{2}$, this supports the proposed mode of action. ${ }^{16}$<smiles>CSc1cccc(=O)c2c(=O)osc12</smiles>

methyl troposulfenin (2)<smiles>O=C(O)c1c(=O)cccc2ssc12</smiles>

tropodithietic acid (1)<smiles>[R]c1ccc(-c2c3cccc(SC)cc-3oc2=O)cc1</smiles>

$\mathrm{R}=\mathrm{H}$, roseobacticide $\mathrm{A}$ $\mathrm{R}=\mathrm{OH}$, roseobacticide $\mathrm{B}$<smiles>O=c1cccc(S)c2soc(=O)c12</smiles>

thiotropocin

troposulfenin<smiles>COc1cc(-c2cc(C(=O)O)cc3c(S(C)(=O)=O)c(O)c(O)c(OC)c23)cc(OC)c1O</smiles>

Figure 1. Structure of tropodithietic acid (TDA, 1) and its isomers thiotropocin and troposulfenin, methyl troposulfenin (2), roseobacticides A and B and roseochelin B.

Inspection of the LC-MS chromatogram of the EtOAc extract of a culture of P. inhibens DSM 17395 revealed an intense peak displaying the characteristic isotopic pattern of the sulfur containing TDA molecule (Figure 2). High resolution mass spectrometry (HRMS) demonstrated the mass of the protonated molecule to be 226.9832 and the predicted formula $\mathrm{C}_{9} \mathrm{H}_{7} \mathrm{O}_{3} \mathrm{~S}_{2}$. A search of the Dictionary of Natural Products, AntiBase and MarinLit revealed no known compounds with this formula, and there are no reported naturally occurring analogues or precursors of $\mathbf{1}$. This formula suggested a structure similar to that of $\mathbf{1}$, but with an additional 
methyl group. Given the high abundance of this compound in the extract and the well described nature of $\mathbf{1}$, we were cautious to confirm this as a true compound and not an artifact of extraction or the analytical method. To this end, we cultured $P$. inhibens DSM 17395 in minimal medium (MM) with D-glucose as the sole carbon source and in parallel using fully substituted D-glucose${ }^{13} \mathrm{C}_{6}$ (Figure 2). It was found that the unknown compound had a mass 9 Da higher when grown on D-glucose- ${ }^{13} \mathrm{C}_{6}$ as the sole carbon source, demonstrating that all carbon atoms were derived by biosynthesis.
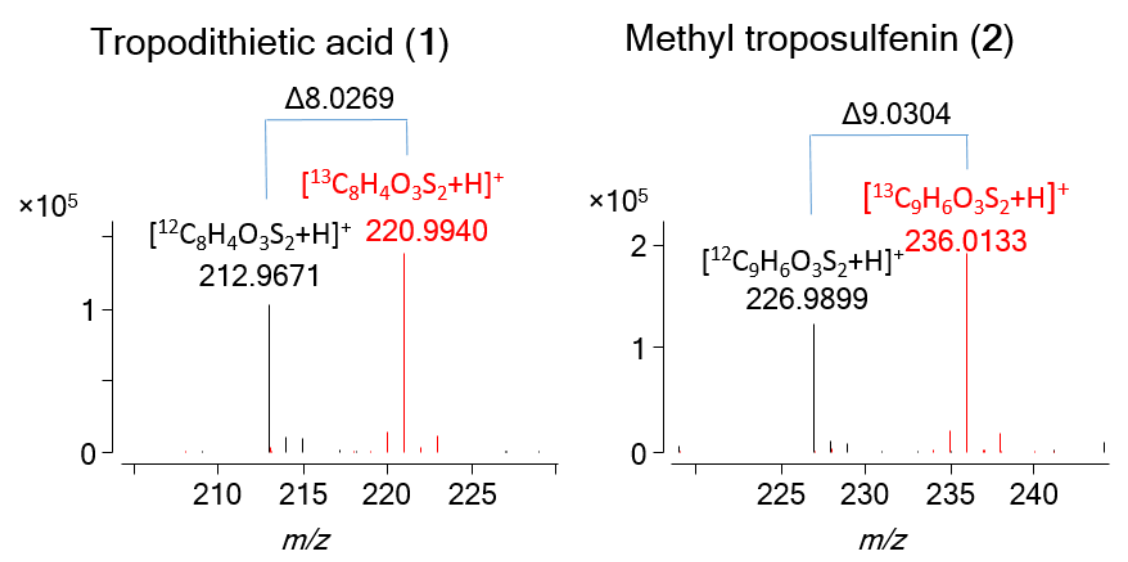

Figure 2. Overlaid mass spectra of TDA (1, left) and methyl troposulfenin (2, right) when grown on D-glucose (black) or D-glucose- ${ }^{13} \mathrm{C}_{6}$ (red).

A two-liter culture of $P$. inhibens DSM 17395 grown for 2 days at $25^{\circ} \mathrm{C}$ was extracted with acidified EtOAc, fractionated using normal phase chromatography, followed by reversed-phase semi-preparative HPLC. It was of vital importance to use an aromatic stationary phase during the reversed-phase purification as the peak shape was poor when using $\mathrm{C} 18$ substituted silica as the stationary phase. It was specifically found that phenyl-hexyl substituted silica as the stationary 
phase provided the best chromatographic separation. For the subsequent structural elucidation, NMR was conducted in THF- $d_{8}$ as $\mathbf{1}$ has poor solubility in most common solvents. Methanol and DMSO were excluded to prevent any possible methyl transfer reactions and due to evidence of strong interactions between DMSO and $\mathbf{1} .{ }^{17}$ The low proton to carbon ratio, high number of heteroatoms and many non-protonated carbon atoms makes structure elucidation more challenging. Nonetheless, the aromatic spin system was easily seen in the COSY spectrum (Figure S1-4) and the HMBC spectrum enabled determination of the remaining carbon scaffold. The key relation was between H-9 of the methyl group and C-4 in the tropone ring (Figure 3), which gave the position of the methylation. The significant shielding of the C-9 of the methyl group supports the attachment via a carbon-sulfur bond rather that an ether linkage. Given that the presence of this methyl group prevents tautomerization, we have chosen to call this molecule methyl troposulfenin (2). Interestingly, although $\mathbf{2}$ has not been reported as a natural product, it was reported by Kintaka et al. ${ }^{10}$ as a synthetic product and as such we sought to compare our natural compound to synthetic material. Compound $\mathbf{1}$ (isolated from above mentioned culture) was dissolved in DMSO and reacted with iodomethane. The semi-synthetic material showed identical retention time, UV-visible, and MS/MS fragmentation pattern as the isolated material (Figure 4).

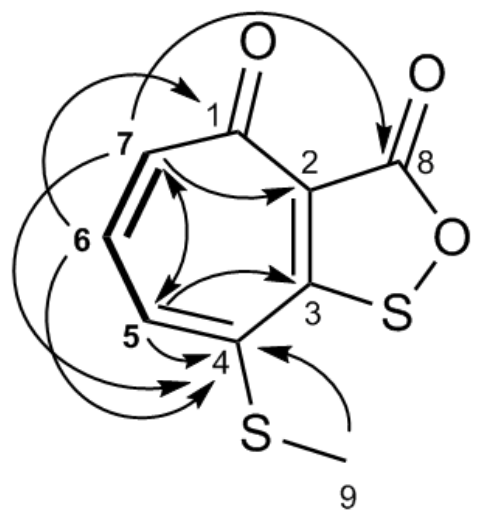


Figure 3. Structure of methyl troposulfenin (2) with HMBC (arrows) and COSY correlations (in bold).
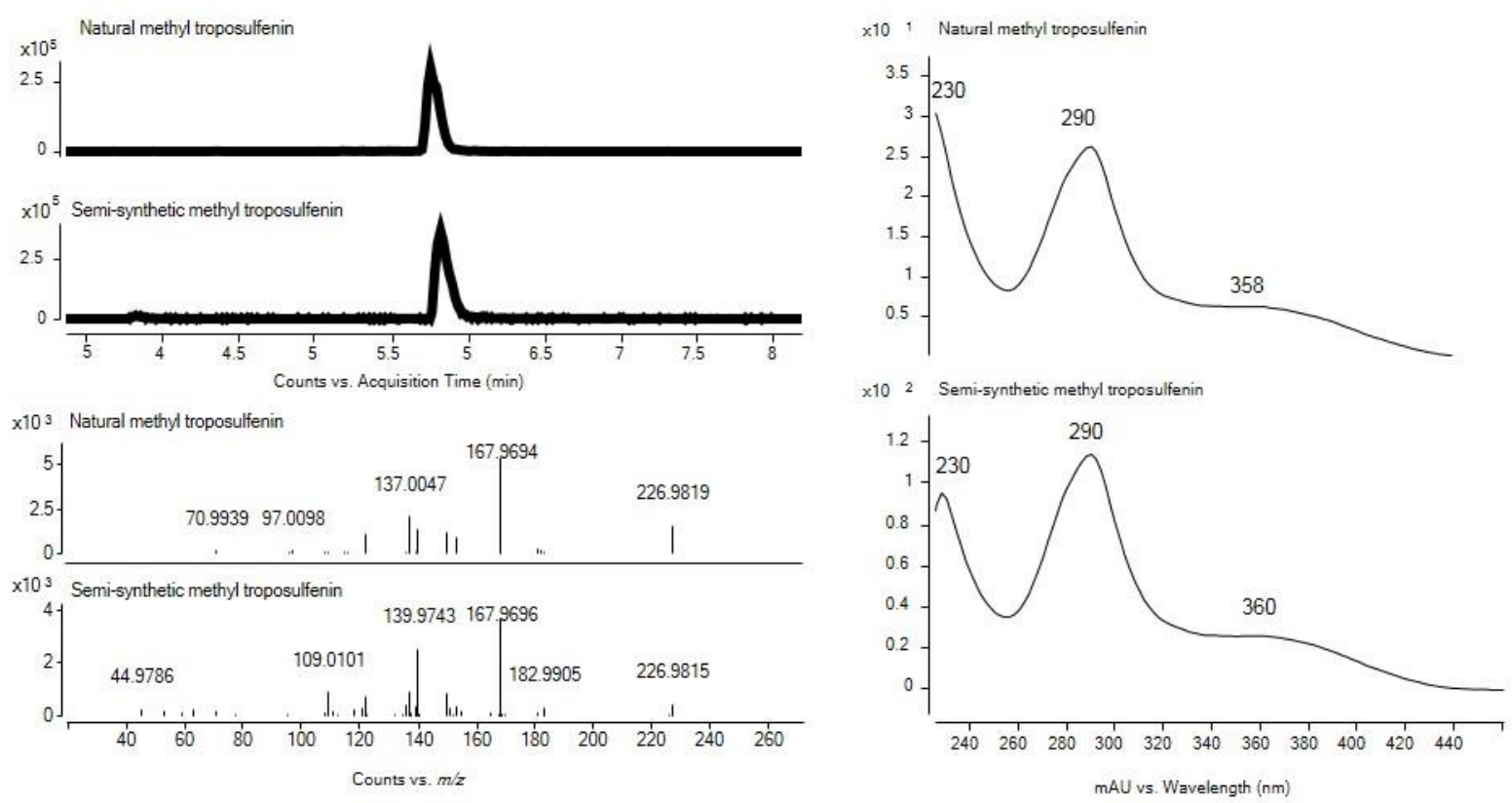

Figure 4. Chromatographic (top left), MS/MS (bottom left) and UV-visible (right) comparison of natural and semi-synthetic methyl troposulfenin (2).

The compounds were tested for antibacterial activity in a well diffusion agar assay against $V$. anguillarum. Compound $\mathbf{1}$ had a higher inhibitory effect against the target in comparison to $\mathbf{2}$ (Table 1). Compound 1 and 2 inhibited the bacterium down to concentrations of $0.01 \mathrm{mM}$ and 1 $\mathrm{mM}$, respectively. This is in agreement with the liquid-based assay, in which $\mathbf{1}$ was also more potent against $V$. anguillarum than $\mathbf{2}$. The minimal inhibitory concentrations of $\mathbf{1}$ and $\mathbf{2}$ against the target strain were $0.03-0.06 \mathrm{mM}$ and $0.25 \mathrm{mM}$, respectively. $\mathrm{IC}_{50} \mathrm{~s}$ (half maximal inhibitory concentrations) were 0.014 and $\sim 0.14 \mathrm{mM}$, respectively (Figure 5). 
Table 1. Inhibition of $V$. anguillarum by 10-fold diluted concentrations of purified TDA (1) or methyl troposulfenin (2) in a well diffusion agar assay.

\begin{tabular}{ccc} 
& \multicolumn{2}{c}{ diameter of inhibition in mm } \\
\cline { 2 - 3 } $\mathrm{mM}$ & TDA (1) & methyl troposulfenin (2) \\
10 & $\mathrm{NA}$ & 11 \\
1 & 16 & 6 \\
0.1 & 11 & 0 \\
0.01 & 3 & 0 \\
0.001 & 0 & 0 \\
0.0001 & 0 & 0 \\
0.00001 & 0 & 0 \\
\hline
\end{tabular}

$\mathrm{NA}=$ not assessed due to too wide diameter of inhibition.

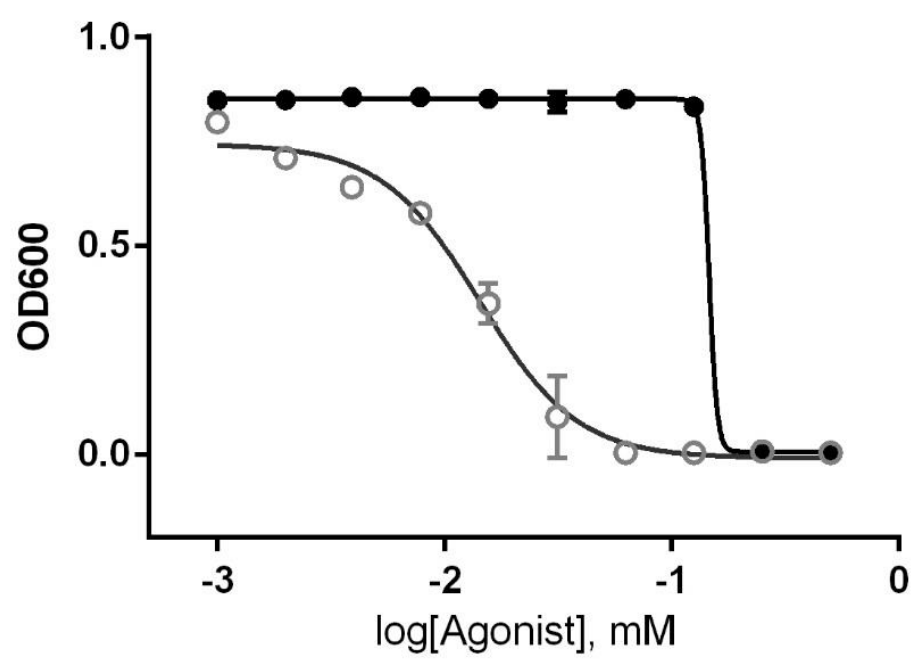

Figure 5. Dose-response analyses of purified TDA (1) (grey rings) or methyl troposulfenin (2) (black dots) against $V$. anguillarum in a liquid-based assay measured as optical density at $600 \mathrm{~nm}$ (OD600) after $24 \mathrm{~h}$ of incubation to determine the minimal inhibitory concentrations as assessed with 2-fold diluted concentrations. $\mathrm{IC}_{50}$ s (half maximal inhibitory concentrations) were 0.014 and $\sim 0.14 \mathrm{mM}$, respectively. Each point is the average of three independent measurements; error bars represent standard deviation of the mean. 
The mode of action of $\mathbf{1}$ was proposed to be disruption of the proton motive force by releasing protons and binding to cations. ${ }^{16}$ Because 2 does not have acidic protons, our results indicate that it has a different impact on cells. To confirm that $\mathbf{2}$ was not simply degraded into $\mathbf{1}$, the inhibition zones were re-extracted and analyzed by LC-MS for the presence of $\mathbf{1}$ and $\mathbf{2}$. Compound $\mathbf{1}$ was not detected in the inhibition zone of the samples containing 2 . This also negates the possibility that $\mathbf{2}$ is acting as a prodrug and being demethylated in the target pathogen.

Methyl troposulfenin is the first structural analogue of TDA identified in nature. This discovery is significant as it is established that TDA has antibacterial effects and that both TDA and roseobacticides are important for algal symbiosis; however this study shows that the abundance of methyl troposulfenin can be up to half of that of TDA in crude extracts and cultures, based on UV-vis absorption at $300 \mathrm{~nm}$. It is unknown how methyl troposulfenin contributes to either of these known functions, but we have established that it does not inhibit a fish pathogenic bacterium as TDA does.

In addition to this, TDA has a highly unusual structure, with a 4-membered dithietane ring fused to a tropone ring. Currently the mechanism of sulfur incorporation is the least understood step in the biosynthesis of TDA. The S-methylation of methyl troposulfenin is likely taking place in a similar manner as observed in the roseochelins.

We have isolated and structurally characterized an S-methylated variant of the known antibiotic TDA (1), namely methyl troposulfenin (2). The methylation on the sulfur position fixes the heterocyclic ring in the "troposulfenin" tautomer. Potentially due to a very different ring system and lack of labile protons, 2 lost the ability to inhibit the growth of Vibrio anguillarum, which is consistent with the proposed mode of action of $\mathbf{1}$. 


\section{EXPERIMENTAL SECTION}

General Experimental Procedures. Infrared spectra were recorded as films on a Bruker Alpha FTIR spectrometer using OPUS version 7.2.

1D and 2D NMR spectra were recorded using an $800 \mathrm{MHz}$ Bruker Avance III spectrometer equipped with a TCI CryoProbe. NMR spectra were acquired using standard pulse sequences. The solvent used was THF- $d_{8}$, which was also used as references with signals at $\delta_{\mathrm{H}} 1.72,3.58 \mathrm{ppm}$ and $\delta_{\mathrm{C}} 25.3,67.2 \mathrm{ppm}$. Data processing and analysis was performed using TopSpin 3.5p17 (Bruker).

Ultra-high Performance Liquid Chromatography-High Resolution Mass Spectrometry (UHPLCHRMS) was performed on an Agilent Infinity 1290 UHPLC system equipped with a diode array detector. UV-Visible spectra were recorded from 190 to $640 \mathrm{~nm}$. MS detection was performed in both positive and negative detection on an Agilent 6545 QTOF MS equipped with Agilent Dual Jet Stream electrospray ion source with a drying gas temperature of $250^{\circ} \mathrm{C}$, gas flow of $8 \mathrm{~L} / \mathrm{min}$, sheath gas temperature of $300{ }^{\circ} \mathrm{C}$ and flow of $12 \mathrm{~L} / \mathrm{min}$. Capillary voltage was set to $4000 \mathrm{~V}$ and nozzle voltage to $500 \mathrm{~V}$.

Bacterial Strains and Growth Media. Two bacterial strains were included in the study; the TDA-producer P. inhibens DSM 17395 and the highly virulent fish pathogenic Vibrio anguillarum strain 90-11-286 ${ }^{18}$ isolated from a diseased rainbow trout (Oncorhynchus mykiss). Liquid broth cultures of $V$. anguillarum were grown in half-strength YTSS broth $\left(1 / 2 \mathrm{YTSS} ; \mathrm{g} \mathrm{L}^{-}\right.$ ${ }^{1}$ yeast extract, $1.25 \mathrm{~g} \mathrm{~L}^{-1}$ tryptone, $2 \mathrm{~g} \mathrm{~L}^{-1}$ Sigma sea salts $)^{19}$ at $25^{\circ} \mathrm{C}$ and $200 \mathrm{rpm}$ on a rotary shaker. For bioassays, $V$. anguillarum was seeded in Instant Ocean (IO) agar plates containing 3 
\% Instant Ocean (Aquarium Systems Inc.), $3.33 \mathrm{~g} \mathrm{~L}^{-1}$ Casamino acids, $4 \mathrm{~g} \mathrm{~L}^{-1}$ glucose, and $10 \mathrm{~g}$ $\mathrm{L}^{-1}$ agar. ${ }^{20} P$. inhibens was grown in $1 / 2 \mathrm{YTSS}, 1 / 2 \mathrm{YTSS}$ supplemented with $0.5 \mathrm{mM} \mathrm{FeCl} 3$ $(1 / 2 \mathrm{YTSS}+\mathrm{Fe})$, mineral medium ${ }^{21}$ supplemented with $5.5 \mathrm{mM}$ D-glucose (MM+glu), or Marine Broth (MB; Difco 2216) at $25{ }^{\circ} \mathrm{C}$ and $200 \mathrm{rpm}$. For ${ }^{13} \mathrm{C}$-labelling, DSM 17395 was pre-cultured in $\mathrm{MM}+$ glu before inoculation into $\mathrm{MM}$ with addition of $5.5 \mathrm{mM}$ D-glucose- $-{ }^{13} \mathrm{C}_{6}\left(99 \%{ }^{13} \mathrm{C}\right.$, Sigma-Aldrich) and in parallel in MM+glu in $100 \mathrm{~mL}$ each. The cultures were incubated for 3 days at $25^{\circ} \mathrm{C}$ and $200 \mathrm{rpm}$.

Extraction and Isolation. A pre-culture of DSM 17395 was inoculated at $1 \%$ in $4 \times 500 \mathrm{~mL}$ MB in $2 \mathrm{~L}$ Erlenmeyer flasks and incubated for two days at $25^{\circ} \mathrm{C}$ and $200 \mathrm{rpm}$. The $2 \mathrm{~L}$ of culture were extracted with EtOAc containing $1 \%$ formic acid $(2 \times 2 \mathrm{~L})$. The phases were separated, the organic phase was collected and the solvent was evaporated. The residue was resuspended in $\mathrm{MeOH} / \mathrm{CH}_{2} \mathrm{Cl}_{2}$ and loaded onto a diol SPE cartridge and fractionated through stepwise elution of heptane/EtOAc. The $45 \% \mathrm{EtOAC} / 55 \%$ heptane fraction was subjected to further purification. The residue was dissolved in 1:1 $\mathrm{MeCN} / \mathrm{H}_{2} \mathrm{O}$ and subjected to gradient elution, beginning at $35 \% \mathrm{MeCN}$ and increasing to $50 \%$ over 20 min, a Phenomenex Gemini C6-Phenyl column $(25 \mathrm{~cm}, 1 \mathrm{~cm}, 5 \mu \mathrm{m}, 110 \AA)$. The extraction yielded $1.0 \mathrm{mg}$ of 2 from $2 \mathrm{~L}$ of bacterial culture.

Methyl troposulfenin (2): yellow solid; UV-visible (MeCN/ $\left.\mathrm{H}_{2} \mathrm{O}\right) \lambda_{\max }(\%) 216$ (100), 290 (75), 360 (17) nm; IR (oil) $v_{\max } 3166,3078,3003,2946,1706,1556,1491,1377,1353,1258,1058$ $\mathrm{cm}^{-1}$; ${ }^{1} \mathrm{H}$ NMR (THF-d8, $\left.800 \mathrm{MHz}\right) \delta 7.39$ (1H, br. d, $\left.J=8.6 \mathrm{~Hz}, \mathrm{H}-5\right), 7.05$ (1H, multiplet, , H6), 6.85 (1H, br.d, $J=12.4, \mathrm{H}-7$ ), 2.64 (3H, s, H-9); ${ }^{13} \mathrm{C}$ NMR (THF- $\left.d_{8}, 200 \mathrm{MHz}\right) \delta 178.7$ (C1), 176.4 (C-3), 167.8 (C-8), 142.9 (C-7), 140.2 (C-5), 135.1 (C-4), 131.8 (C-6), 117.8 (C-2), 20.9 (C-9); HRESIMS $m / z 226.9827[\mathrm{M}+\mathrm{H}]^{+}$(calcd for $\mathrm{C}_{9} \mathrm{H}_{6} \mathrm{O}_{3} \mathrm{~S}_{2}{ }^{+}, 226.9831$ ) 
Bioassays. To synthesize 2, $1(1.0 \mathrm{mg}, 4.7 \mu \mathrm{mol})$ was dissolved in acetone $(5 \mathrm{~mL})$ and iodomethane $(114 \mathrm{mg}, 50 \mu \mathrm{L}, 0.8 \mathrm{mmol})$ was added. The solution was stirred for $48 \mathrm{~h}$ and the solvent was removed by evaporation under a stream of nitrogen. The resulting 2 was resuspended in $\mathrm{MeOH}$ and showed identical chemical properties to the authentic material obtained from the extractions from $P$. inhibens culture.

The antimicrobial activities of pure $\mathbf{1}$ and $\mathbf{2}$ were assessed against $V$. anguillarum in a well diffusion agar assay by seeding the pathogen in IO agar plates. ${ }^{22}$ The supernatants, extracts, and tenfold dilutions of the pure compounds $(50 \mu \mathrm{L} ; 10 \mathrm{mM}$ to $0.00001 \mathrm{mM})$ were added to wells (diameter $=8 \mathrm{~mm}$; distance between the wells $=32-38 \mathrm{~mm}$ ) punched into the agar plate alongside medium and $\mathrm{MeOH}$ controls. Following $48 \mathrm{~h}$ of incubation, the diameter of the resulting inhibition zones were measured.

The minimal inhibitory concentrations (MIC) of $\mathbf{1}$ and $\mathbf{2}$ against $V$. anguillarum were assessed in a 96-well microtiter plate assay. A $5 \mathrm{~mL}$ 1/2YTSS culture of $V$. anguillarum was grown overnight at $25^{\circ} \mathrm{C}$ and $200 \mathrm{rpm}$, and the culture was re-inoculated to an optical density at $600 \mathrm{~nm}$ of 0.01 into triplicate wells of a 96-well microtiter plate containing $200 \mu \mathrm{L} 1 / 2$ YTSS supplemented with either 1 or 2 in twofold decreasing concentrations (from 500 to $1 \mu \mathrm{M}$ ). Solvent and controls without bacteria were included. The MIC was determined after $24 \mathrm{~h}$ incubation at $25^{\circ} \mathrm{C}$ as the concentration, at which the growth of the pathogen was visibly impaired. The dose-response curves of the two compounds were analyzed using nonlinear least-squares regression.

\section{Supporting Information}

The Supporting Information is available free of charge on the ACS Publications website at DOI: 
${ }^{1} \mathrm{H}$ NMR, HMBC, HSQC, and COSY spectra of 2 (PDF)

AUTHOR INFORMATION

Corresponding Author

*Tel: +45 452525 18. E-mail: evaso@bio.dtu.dk

\section{ORCID}

Christopher B. W. Phippen 0000-0002-9536-7387

Cecilie M. Jørgensen 0000-0003-0863-3171

Mikkel Bentzon-Tilia 0000-0002-7888-9845

Charlotte Held Gotfredsen 0000-0002-7386-119X

Thomas O. Larsen 0000-0002-3362-5707

Lone Gram: 0000-0002-1076-5723

Eva Sonnenschein: 0000-0001-6959-5100

\section{Present Addresses}

$\S$ Novo Nordisk A/S, Novo Nordisk Park, 2760 Måløv, Denmark

\section{Author Contributions}

The manuscript was written through contributions of all authors. All authors have given approval to the final version of the manuscript.

\section{Funding Sources}


This work was supported by grant VKR023285 from the Villum Foundation, and by the Seventh Framework Programmes MaCuMBA (KBBE-2012-6-311975), PharmaSea (KBBE-2012-6312184) from the European Union and the Danish National Research Foundation (DNRF137) for the Center for Microbial Secondary Metabolites.

\section{ACKNOWLEDGMENT}

The NMR Center • DTU and the Villum foundation are acknowledged for access to the 800 MHz spectrometer.

\section{REFERENCES}

(1) Food and Agriculture Organization of the United Nations. 2016.

(2) Verschuere, L.; Rombaut, G.; Sorgeloos, P.; Verstraete, W. Microbiol. Mol. Biol. Rev. 2000, 64, 655-671. https://doi.org/10.1128/MMBR.64.4.655-671.2000.

(3) Rasmussen, B. B.; Erner, K. E.; Bentzon-Tilia, M.; Gram, L. Microb. Biotechnol. 2018, 11, 1070-1079. https://doi.org/10.1111/1751-7915.13275.

(4) D’Alvise, P. W.; Lillebø, S.; Prol-Garcia, M. J.; Wergeland, H. I.; Nielsen, K. F.; Bergh, Ø.; Gram, L. PLoS One 2012, 7, e43996. https://doi.org/10.1371/journal.pone.0043996.

(5) D’Alvise, P. W.; Lillebø, S.; Wergeland, H. I.; Gram, L.; Bergh, Ø. Aquaculture 2013, 384387, 82-86. https://doi.org/10.1016/j.aquaculture.2012.12.013.

(6) Grotkjær, T.; Bentzon-Tilia, M.; D’Alvise, P.; Dierckens, K.; Bossier, P.; Gram, L. Aquaculture 2016, 462, 64-69. https://doi.org/10.1016/j.aquaculture.2016.05.001. 
(7) Porsby, C. H.; Webber, M. a; Nielsen, K. F.; Piddock, L. J. V; Gram, L. Antimicrob. Agents Chemother. 2011, 55, 1332-1337. https://doi.org/10.1128/AAC.01222-10.

(8) Rasmussen, B. B.; Grotkjær, T.; D’Alvise, P. W.; Yin, G.; Zhang, F.; Bunk, B.; Spröer, C.; Bentzon-Tilia, M.; Gram, L. Appl. Environ. Microbiol. 2016, 82, 4802-4810. https://doi.org/10.1128/AEM.01047-16.

(9) Brinkhoff, T.; Bach, G.; Heidorn, T.; Liang, L.; Schlingloff, A.; Simon, M. Appl. Environ. Microbiol. 2004, 70, 2560-2565. https://doi.org/10.1128/AEM.70.4.2560-2565.2003.

(10) Kintaka, K.; Ono, H.; Tsubotani, S.; Harada, S.; Okazaki, H. J. Antibiot. (Tokyo). 1984, 37, $1294-1300$.

(11) Greer, E.; Aebisher, D.; Greer, A.; Bentley, R. J. Org. Chem. 2008, 73, 280-283.

(12) Seyedsayamdost, M. R.; Carr, G.; Kolter, R.; Clardy, J. J. Am. Chem. Soc. 2011, 133, $18343-18349$.

(13) Wang, R.; Seyedsayamdost, M. R. Org. Lett. 2017, 19, 5138-5141. https://doi.org/10.1021/acs.orglett.7b02424.

(14) Sonnenschein, E. C.; Phippen, C. B. W.; Bentzon-Tilia, M.; Rasmussen, S. A.; Nielsen, K. F.; Gram, L. Environ. Microbiol. Rep. 2018, 10, 383-393. https://doi.org/10.1111/17582229.12649 .

(15) Wang, R.; Gallant, É.; Seyedsayamdost, M. R. MBio 2016, 7, e02118-15. https://doi.org/10.1128/mBio.02118-15.

(16) Wilson, M. Z.; Wang, R.; Gitai, Z.; Seyedsayamdost, M. R. Proc. Natl. Acad. Sci. 2016, 
113, 1630-1635. https://doi.org/10.1073/pnas.1518034113.

(17) D’Alvise, P. W.; Phippen, C. B. W.; Nielsen, K. F.; Gram, L. Appl. Environ. Microbiol. 2016, 82, 502-509. https://doi.org/10.1128/AEM.02992-15.

(18) Skov, M. N.; Pedersen, K.; Larsen, J. L. Appl. Environ. Microbiol. 1995, 61, 1540-1545.

(19) Sobecky, P. A.; Mincer, T. J.; Chang, M. C.; Helinski, D. Appl. Environ. Microbiol. 1997, $63,888-895$.

(20) Gram, L.; Melchiorsen, J.; Bruhn, J. Mar. Biotechnol. (NY). 2010, 12, 439-451.

(21) Zech, H.; Thole, S.; Schreiber, K.; Kalhöfer, D.; Voget, S.; Brinkhoff, T.; Simon, M.; Schomburg, D.; Rabus, R. Proteomics 2009, 9, 3677-3697.

(22) Hjelm, M.; Bergh, O.; Riaza, A.; Nielsen, J.; Melchiorsen, J.; Jensen, S.; Duncan, H.; Ahrens, P.; Birkbeck, H.; Gram, L. Syst. Appl. Microbiol. 2004, 27, 360-371. https://doi.org/10.1078/0723-2020-00256. 


\section{TOC Graphic}
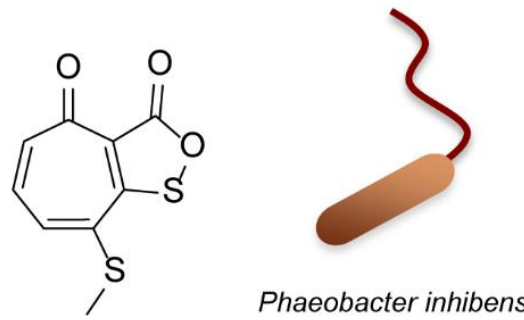